\title{
Botulinum toxin injections for blepharospasm prior to ocular surgeries
}

This article was published in the following Dove Press journal:

Clinical Ophthalmology

13 April 2012

Number of times this article has been viewed

\section{Seydi Okumus' \\ Erol Coskun' \\ İbrahim Erbagci' \\ M Gürkan Tatar ${ }^{2}$ \\ Aysegul Comez' \\ Erdal Kaydu' \\ Ramazan Yayuspayi' \\ Bulent Gurler' \\ 'Department of Ophthalmology, University of Gaziantep, \\ ${ }^{2}$ Ophthalmology Clinic, Nizip State \\ Hospital, Nizip, Gaziantep, Turkey}

Correspondence: Seydi Okumus Department of Ophthalmology, Faculty of Medicine, University of Gaziantep, Gaziantep 27310,Turkey Tel +90342360 6060 ext 76545 Fax +903423601617

Email seydiokumus@hotmail.com
Purpose: The aim of this study was to show the efficiency of preoperative botulinum toxin A (Botox A) in patients with benign essential blepharospasm who were to undergo ocular surgery with local anesthesia.

Materials and methods: Twenty-eight benign essential blepharospasm patients who were administered unilateral Botox A prior to ocular surgery between January 2004 and May 2011 were included in this study. Eleven cases had pterygiums, ten had cataracts, and four had glaucomas, while the remaining three had aphakia. All cases' severity of spasm (stage 0-4) and eyelid closing forces (stage 1-4) were evaluated according to the Jankovic scale prior to the injection, at 3 days, 14 days, 1 month, and 3 months after Botox A injection.

Results: Of the patients enrolled in the study, 16 were female and 12 were male, with an average age of $55.52 \pm 1.53$ years (52-65). Average onset of the Botox injection's effect was $2.8 \pm 0.9$ (2-5) days. Its effect lingered for about $11.5 \pm 3.6(8-22)$ weeks. The severity of spasm and eyelid closing forces of all the patients enrolled were compared prior to the injection at 3 and 14 days and the first and third months after the injection. There were statistically significant differences between prior to the injection and 3 days $(P=0.001), 14$ days $(P<0.001)$ and 1 month after the injection $(P<0.001)$. There was no statistically significant difference between prior to the injection and 3 months after the injection $(P=0.513)$. Fourteen days following the injection, the surgeries were successfully performed.

Conclusion: Botox A administered prior to ocular surgery will control both blepharospasm and lower the risks that can be encountered before and during surgery, thus increasing the comfort of the patient and the surgeon.

Keywords: botulinum toxin A, blepharospasm, ocular surgery

\section{Introduction}

Benign essential blepharospasm (BEB) is thought to be due to overexcitement of the neurons in the brain stem that results from the organic dysfunction of the basal ganglia, characterized by involuntary overcontraction of the orbicularis oculi. ${ }^{1-3}$ BEB typically has an onset in the sixth decade, and it is more common in women. ${ }^{4}$ The main symptoms of blepharospasm are grumbling facial expression, fluttering of eyelids, increase in the frequency of blinking, and chronic involuntary contractions that eventually affect both eyes. In cases with BEB, tonic essential spasm of the orbicularis oculi muscle can lead to total closure of both eyelids. ${ }^{5}$ As a result, activities such as reading, writing, and driving become hard to accomplish for patients, with blepharospasms having a negative effect on the quality of life. ${ }^{6}$ 
Botulinum toxin type A (Botox A) enables neuromuscular blockade by preventing acetylcholine secretion from the presynaptic vesicles. Botox A is currently the gold-standard therapy of benign essential blepharospasm due to its efficiency and safety. ${ }^{7,8}$

Ocular surgeries can be performed by using topical or local anesthetics. However, performing surgery in patients with tonic contraction of eyelids could be hard for both the surgeon and the patient. Additionally, preoperative anxiety of the patient, preoperative pain, and exposure to the light of the surgery microscope can cause an increase in the frequency of blinking and involuntary contractions. Surgery in a patient with persistent involuntary contractions of the eyelids is an undesired condition. The aim of this study was to show the efficacy of Botox A in patients with benign essential blepharospasm who were to undergo ocular surgery under local anesthesia.

\section{Materials and methods}

Twenty-eight BEB patients who were administered with unilateral Botox A prior to ocular surgery between January 2004 and May 2011 were included in this study. Eleven cases had pterygiums, ten had cataracts, and four had glaucomas, while the remaining three had aphakia. The diagnosis of BEB was ascertained by detailed ophthalmic and neurological examination. Patients who had systemic and neurological disorders and those who had previous Botox A injections were excluded from the study. Prior to the study, informed consent was obtained from the patients and local ethics committee approvals were completed according to Declaration of Helsinki. Severity of spasm (stage 0-4) and eyelid closing force (stage 1-4) were evaluated according to the Jankovic scale prior to the injection and at 3 days, 14 days, 1 month, and 3 months after Botox A injection ${ }^{9,10}$ (Table 1).

A Botox A vial (100 U) was diluted with $4 \mathrm{~mL}$ of saline that included no preservatives $(0.9 \% \mathrm{NaCl})$. After the dilution,

Table I Severity of spasm and eyelid closing force scores

\begin{tabular}{ll}
\hline Grade & Definition \\
\hline Severity of spasm & \\
0 & No spasm \\
\hline & Mild spasm at stimulation only \\
2 & Visible spasm without impairment of daily life \\
3 & Visible spasm with impairment of daily life \\
4 & Severe spasm with impairment of daily life \\
Eyelid closing force & \\
\hline & Flaccid \\
2 & Overcome with minimum resistance \\
3 & Overcome with moderate resistance \\
4 & Normal strength \\
\hline
\end{tabular}

a solution that had $2.5 \mathrm{U}$ of Botox $\mathrm{A}$ in each $0.1 \mathrm{~mL}$ was obtained. The areas that would be injected were marked after being cleansed by $10 \%$ povidone iodine solution. No other drugs were used, in order to prevent drug interaction. From the solution obtained, six injections were made with a 27-gauge insulin syringe. These injections were made to lateral and medial connections of the preseptal and orbital parts of the orbicularis oculi muscle, lateral and medial part of the pretarsal orbicularis oculi muscle of the upper eyelid, lateral part of the lateral canthus, and pretarsal region of the lower eyelid (Figure 1). Compression was performed in the areas where injections were made. The severity of spasm and eyelid closing force for all the patients enrolled were measured according to the Jankovic scale prior to the injection and at 3 days, and 14 days, 1 month, and 3 months after injection and compared.

Fourteen days after the injection, patients underwent ocular surgery under topical and/or sub-Tenon's anesthesia by using eye speculum. Topical anesthesia was provided by $0.5 \%$ proparacaine drops (Alcaine ${ }^{\circledR}$; Alcon Laboratories, Inc, Fort Worth, TX), while sub-Tenon's anesthesia was provided by a 2-cc injection of lidocaine $\mathrm{HCl} 20 \mathrm{mg} / \mathrm{mL}$, epinephrine HCI $0.0125 \mathrm{mg} / \mathrm{mL}$ (Jetocain; Adeka, Samsun, Turkey). No sedatives were used for patients that may have interrupted the blepharospasm symptoms. The patients were evaluated for anterior segment and fundus, and intraocular pressure (IOP) was measured after operation.

Statistical analyses were performed using the Statistical Package for the Social Sciences (version 12.0; IBM, Armonk, NY). The Wilcoxon signed-rank test was used for the statistical analysis of severity of spasm and eyelid closing force prior to the injection and after injection. A $P$ value of $<0.05$ was accepted as statistically significant.

\section{Results}

Of the 28 patients enrolled in the study, 16 were female and 12 were male. The average age of the patients was

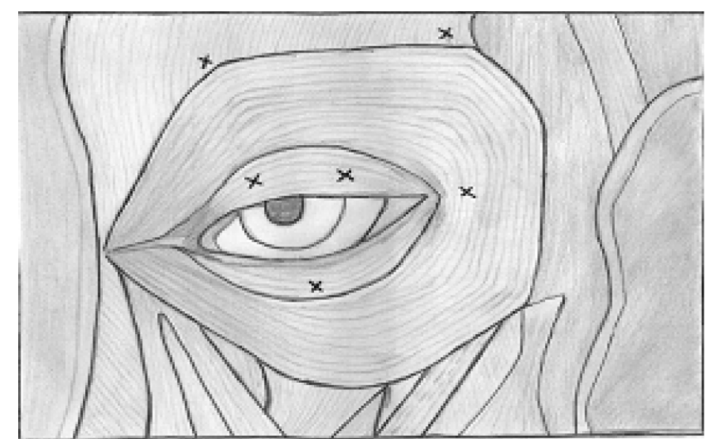

Figure I Location of injections of Botox A. Note: Arrows indicate orientation of the tip of needle. 
$55.52 \pm 1.53$ years ( $52-65$ years). Eye specula were used on all patients without trouble. There were not any complications due to involuntary eyelid contractions during surgery. Eleven eyes of eleven patients underwent pterygium excision and conjunctival autograft surgeries under subconjunctival anesthesia. Ten eyes of ten patients underwent phacoemulsification and intraocular lens implantation surgeries for cataract under topical anesthesia. Four patients underwent trabeculectomy under retrobulbar anesthesia. Three patients underwent secondary intraocular lens implantation under sub-Tenon's anesthesia (Table 2).

The severity of spasm and eyelid closing forces of all the patients enrolled were compared prior to the injection and at 3 days, 14 days and 1 and 3 months after the injection. There were statistically significant differences between prior to the injection and 3 days $(P=0.001), 14$ days $(P=0.001)$ and 1 month after the injection $(P=0.001)$. There was no statistically significant difference between prior to the injection and 3 months after the injection $(P=0.513)$ (Table 3$)$.

Corneal sutures of the patients who were given intraocular lenses with scleral fixation due to aphakia were removed in an average of $36.6 \pm 6$ days (30-42 days).

The average corrected preoperative visual acuity of the patients with cataract was $20 / 200(20 / 640-20 / 80)$, while the postoperative value was 20/32 (20/80-20/25). Preoperative and postoperative values for patients who were given intraocular lenses with scleral fixation were 20/400 and 20/50, respectively. Preoperative and postoperative average IOP values for patients with glaucoma were $28.7 \pm 3.6 \mathrm{mmHg}$ and $18 \pm 3.2 \mathrm{mmHg}$, respectively. Average onset of the Botox injection's effect was $2.8 \pm 0.9$ (2-5) days. Its effect lingered for about $11.5 \pm 3.6(8-22)$ weeks. In follow-ups, it was determined that the effects of the injections were more evident on the 14th day and that the level of decrease in the blepharospasm degree and eyelid power was sufficient to let the eye speculum to be fastened.

None of the patients experienced diplopia, dry eye, keratitis, pain, lacrimation, blurry vision, or any systemic side effects.
Eyelid echimosis was observed in two patients, while there was mild ptosis in one patient on the fourth postoperative day. The ptosis resolved on its own in approximately 2 months.

\section{Discussion}

Botox A is commonly used in the control of BEB, strabismus hemifacial spasm, cervical dystonia, spasticity, spastic entropion, thyroid-associated upper eyelid contraction, and also it is used as an alternative to surgical tarsorrhaphy in cases with ocular surface disorders. ${ }^{7,811-19}$ The toxin has received Food and Drug Administration approval for treatment of blepharospasm, strabismus, primary axillary hyperhidrosis, cervical dystonia and glabellar wrinkles, and brow furrows. ${ }^{20,21}$ Our indication for administrating Botox A may be presented as a novel one. BEBs of the patients were controlled by preoperative Botox injection, and the surgeries were performed under local anesthesia. Postoperative examinations of the patients were performed, procedures like IOP value were measured by using applanation tonometer, and the removal of corneal sutures were done easily. There are no reports in literature concerning the anesthesia options for blepharospasm patients who will undergo ocular surgery. Botox A injection prior to ocular surgery will increase the patient and the surgeon's comfort alike.

Applying an eye speculum is a must in order to perform ocular surgery. However, this may be difficult in cases with blepharospasm. After establishment of the eye speculum in BEB patients during eye surgery, involuntary closure of the eyelid due to blepharospasm will lead to an elevation in intraorbital and intraocular pressure. Periodical contractions of eyelids and fluctuation of IOP due to this contraction are crucial in phacoemulsification because increments of IOP could complicate capsulorhexis, and as a result anterior chamber depth cannot be preserved. Capsular tear and endothelial damage due to reduction in anterior chamber depth can be encountered. In glaucoma surgeries and scleral fixation secondary intraocular lens implantation, there can be rapid decreases in intraocular pressures. In such instances,

Table 2 Subject details

\begin{tabular}{lllrl}
\hline Disease & $\mathbf{n}$ & $\mathbf{f} / \mathbf{m}$ & Mean age (year) & Type of anesthesia \\
\hline Pterygium & $1 \mathrm{n} / \%$ & $56.3 \pm 2.1 \mathrm{I}$ & Subconjunctival anesthesia \\
Cataract & 10 & $5(63.6) / 4(36.4)$ & $53.24 \pm 1.14$ & Topical anesthesia \\
Glaucoma & 4 & $2(50) / 2(50)$ & $57.87 \pm 4.12$ & Retrobulbar anesthesia \\
Aphakia & 3 & $2(66.6) / I(33.4)$ & $54.7 \pm 3.21$ & Sub-Tenon's anesthesia \\
All cases & 28 & $16(57.1) / / 2(42.9)$ & $55.52 \pm 1.53$ & \\
\hline
\end{tabular}

Note: Values are means \pm standard deviation.

Abbreviations: $n$, number; $f$, female; $m$, male. 
Table 3 Comparison of severity of spasm and eyelid closing force scores before and after Botox A injection

\begin{tabular}{|c|c|c|c|c|c|c|}
\hline & BI & Al 3rd day & Al I4th day & Al Ist month & Al 3rd month & $P$ \\
\hline SS & $2.78 \pm 0.62$ & $2.21 \pm 0.49$ & $1.07 \pm 0.60$ & $1.46 \pm 0.50$ & $2.89 \pm 0.78$ & $\begin{array}{l}(P=0.00 \mathrm{I}),(P<0.00 \mathrm{I}), \\
(P<0.00 \mathrm{I}),(P=0.5 \mathrm{I} 3)\end{array}$ \\
\hline ECF & $2.89 \pm 0.73$ & $2.17 \pm 0.47$ & $1.14 \pm 0.35$ & $1.46 \pm 0.50$ & $2.92 \pm 0.7 \mid$ & $\begin{array}{l}(P=0.001),(P<0.001), \\
(P<0.001),(P=0.833)\end{array}$ \\
\hline
\end{tabular}

Notes: Data are shown as means \pm standard deviation. The Wilcoxon signed-rank test was used for statistical analysis. A $P$ value of less than 0.05 was considered statistically significant.

Abbreviations: BI, before injection; Al, after injection; SS, severity of spasm; ECF, eyelid closing force.

involuntary contractions of eyelids may pose as a threat for maintenance of anterior chamber depth. It is known that glaucoma and previous anterior vitrectomies and hypotonia are risk factors for expulsive hemorrhage. ${ }^{22}$ It is important to prevent involuntary eyelid contractions and to avoid complications such as expulsive hemorrhage that can result from pulsatile intraocular pressure elevation. Endothelial damage could occur due to pulsatile contraction of eyelids in the patients who underwent intraocular lens implantation with scleral fixation. Preoperative application of Botox could protect patients having ocular surgery under local anesthesia from these potential risks. Preoperative paralyzation of the orbitacularis oculi by using local anesthetic drugs in ocular surgery of BEB patients was performed easily and safely. General anesthesia can be used as an alternative. With the aid of these procedures, perioperative akinesis was able to be achieved in both groups via safe and comfortable surgery, but long-term symptomatic healing and comfort in postoperative controls cannot be achieved by procedures other than Botox injection in BEB. Moreover, general anesthesia has some disadvantages, including premedication necessity, increase in the duration of the surgery, possible complications of general anesthesia, and increase in hospital admission duration postoperatively.

Average onset of the Botox injection's effect was $2.8 \pm 0.9(2-5)$ days in our patients. According to the literature, Botox's effect starts on the third day; the maximum effect of Botox sets in 14 days after injection. ${ }^{11,23}$ Therefore, the surgeries were performed 14 days after the injection. However, the time of surgery can be determined according to the patient's status after day 3 , when the effect of Botox starts. Botox's effect lingered for about $11.5 \pm 3.6$ weeks. This duration is enough for most eyes' rehabilitation. Ocular surgery and postoperative examinations of the patients were performed during this period, IOP values were measured, and the corneal sutures were removed easily. In studies in which long-term follow-ups were conducted of blepharospasm patients who had been administered Botox A, it was reported that the effect lasts 14 to 16 weeks. ${ }^{11,17,24}$ The effect of the drug fades when the axons elongate and new neuromuscular junctions are formed.

In the control of blepharospasm, Botox A can be injected in pretarsal and preseptal regions. In our patients, we preferred the pretarsal injection, due to it being closer to the eyelid, more efficient, and having fewer complications. Some studies report that the frequency of involuntary blinking decreases more and that there are less complications with pretarsal administration, which makes it more efficient than other techniques. ${ }^{25-27}$ It has been reported that the average initial dose in the control of blepharospasm is between 1.25 and $5 \mathrm{U} .^{28}$ We used $2.5 \mathrm{U}$, and this dose was enough for all patients.

After Botox injection, complications such as eyelid ecchymosis, ptosis, diplopia, and watery eyes after injection in medial cantus region were reported. Following injection, there was eyelid echimosis in two patients (7\%) and ptosis in one patient (3.6\%). In some studies, it was reported that postinjection ptosis rates varied between $10.3 \%$ and $9.2 \%$, and chemosis rates were between $7 \%$ and $8.2 \% .{ }^{11,29}$ Our ptosis rates were much lower than the previous studies, suggesting these values were due to our preference of pretarsal injection.

\section{Conclusion}

Pretarsal Botox A injection in BEB patients prior to ocular surgery is an efficient and safe procedure that helps the surgery to be performed under local or topical anesthesia. Additionally, by using this procedure, postoperative examination and postoperative intervention on the eye can be performed easily.

\section{Disclosure}

The authors report no conflicts of interest in this work.

\section{References}

1. Jankovic J, Orman J. Blepharospasm: demographic and clinical survey of 250 patients. Ann Ophthalmol. 1984;16(4):371-376.

2. Grandas F, Elston J, Quinn N, Marsden CD. Blepharospasm: a review of 264 patients. J Neurol Neurosurg Psychiatry. 1988;51(6):767-772. 
3. Vitek JL, Bakay RA, Freeman A, et al. Randomized trial of pallidotomy versus medical therapy for Parkinson's disease. Ann Neurol. 2003;53(5):558-569.

4. Anderson RL, Patel BC, Holds JB, Jordan DR. Blepharospasm: past, present, and future. Ophthal Plast Reconstr Surg. 1998;14(5): 305-317.

5. Jankovic J, Havins WE, Wilkins RB. Blinking and blepharospasm. Mechanism, diagnosis, and management. JAMA. 1982;248(23): 3160-3164.

6. Reimer J, Gilg K, Karow A, Esser J, Franke GH. Health-related quality of life in blepharospasm or hemifacial spasm. Acta Neurol Scand. 2005;111(1):64-70.

7. Osako M, Keltner JL. Botulinum A toxin (Oculinum) in ophthalmology. Surv Ophthalmol. 1991;36(1):28-46.

8. Ozkan SB, Can D, Söylev MF, Arsan AK, Duman S. Chemodenervation in treatment of upper eyelid retraction. Ophthalmologica. 1997; 211(6):387-390.

9. Khoo HM, Kim JC, Khoo BS. Treatment of blepharospasm and hemifacial spasm with botulinum toxin A. Korean J Ophthalmol. 1990;31(1):59-68.

10. Kim JC, Kim WS, Ahn SK, Shyn KH. Clinical studies in patients with essential blepharospasm and with hemifacial spasm. Korean $J$ Ophthalmol. 1991;32(10):837-843.

11. Cillino S, Raimondi G, Guépratte N, et al. Long-term efficacy of botulinum toxin A for treatment of blepharospasm, hemifacial spasm, and spastic entropion: a multicentre study using two drug-dose escalation indexes. Eye. 2010;24(4):600-607.

12. Dutton JJ, Buckley EG. Long-term results and complications of botulinum A toxin in the treatment of blepharospasm. Ophthalmology. 1988;95(11):1529-1534.

13. Scott AB, Rosenbaum A, Collins CC. Pharmacologic weakening of extraocular muscles. Invest Ophthalmol. 1973;12(12):924-927.

14. Keen M, Kopelman JE, Aviv JE, Binder W, Brin M, Blitzer A Botulinum toxin A: a novel method to remove periorbital wrinkles. Facial Plast Surg. 1994;10(2):141-146.

15. Brandt FS, Bellman B. Cosmetic use of botulinum A exotoxin for the aging neck. Dermatol Surg. 1998;24(11):1232-1234.
16. Scott AB. Botulinum toxin injection into extraocular muscles as an alternative to strabismus surgery. Ophthalmology. 1980;87(10): 1044-1049.

17. Ellis MF, Daniell M. An evaluation of the safety and efficacy of botulinum toxin type A (Botox) when used to produce a protective ptosis. Clin Experiment Ophthalmol. 2001;29(6):394-399.

18. Sahlin S, Chen E, Kaugesaar T, Almqvist H, Kjellberg K, Lennerstrand $\mathrm{G}$. Effect of eyelid botulinum toxin injection on lacrimal drainage. Am J Ophthalmol. 2000;129(4):481-486.

19. Brashear A. Botulinum toxin type A: exploring new indications. Drugs Today (Barc). 2010;46(9):671-682.

20. Gürsoy D, Öztürk S. Botox treatment and common treatment indications. Turkiye Klinikleri J Med Sci. 2009;29(1):102-103.

21. Durmazlar SPK, Eskioğlu F. Botulinum toxin (fundamentals before practice). Turkiye Klinikleri J Med Sci. 2009;29(3):702-707.

22. Goldsmith C, Rene C. Massive spontaneous expulsive suprachoroidal haemorrhage in a blind glaucomatous eye treated with chronic topical steroid. Eye. 2003;17(3):439-440.

23. Gill HS, Kraft SP. Long-term efficacy of botulinum a toxin for blepharospasm and hemifacial spasm. Can J Neurol Sci. 2010;37(5): 631-636.

24. Ainsworth JR, Kraft SP. Long-term changes in duration of relief with botulinum toxin treatment of essential blepharospasm and hemifacial spasm. Ophthalmology. 1995;102(12):2036-2040.

25. Cakmur R, Ozturk V, Uzunel F, Donmez B, Idiman F. Comparison of preseptal and pretarsal injections of botulinum toxin in the treatment of blepharospasm and hemifacial spasm. J Neurol. 2002;249(1):64-68.

26. Jankovic J. Apraxia of lid opening. Mov Disord. 1995;10(5):686-687.

27. Jankovic J. Pretarsal injection of botulinum toxin for blepharospasm and apraxia of eyelid opening. J Neurol Neurosurg Psychiatry. 1996;60(6):704.

28. Költringer P, Haselwander H, Reisecker F. The treatment of blepharospasm with botulinum toxin A. Wien Klin Wochenschr. 1990;13;102(14):403-407.

29. Yoon JS, Kim JC, Lee SY. Double-blind, randomized, comparative study of Meditoxin versus Botox in the treatment of essential blepharospasm. Korean J Ophthalmol. 2009;23(3):137-141.
Clinical Ophthalmology

\section{Publish your work in this journal}

Clinical Ophthalmology is an international, peer-reviewed journal covering all subspecialties within ophthalmology. Key topics include: Optometry; Visual science; Pharmacology and drug therapy in eye diseases; Basic Sciences; Primary and Secondary eye care; Patient Safety and Quality of Care Improvements. This journal is indexed on

\section{Dovepress}

PubMed Central and CAS, and is the official journal of The Society of Clinical Ophthalmology (SCO). The manuscript management system is completely online and includes a very quick and fair peer-review system, which is all easy to use. Visit http://www.dovepress.com/ testimonials.php to read real quotes from published authors. 